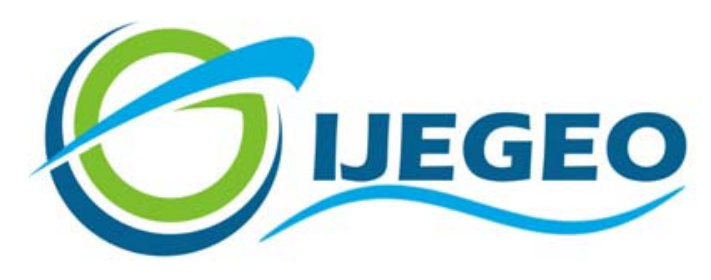

International Journal of Environment and Geoinformatics (IJEGEO) is an international, multidisciplinary, peer reviewed, open access journal.

\title{
Soil Moisture Estimation using Sentinel-1 SAR data and Land Surface Temperature in Panchmahal district, Gujarat State
}

\section{Sachin SUTARIYA., Ankur HIRAPARA, Momin MEHERBANALI, M.K. TIWARI, Vijay SINGH, Manik H. KALUBARME}

\author{
Chief in Editor \\ Prof. Dr. Cem Gazioğlu \\ Co-Editors \\ Prof. Dr. Dursun Zafer Şeker, Prof. Dr. Şinasi Kaya, \\ Prof. Dr. Ayşegül Tanık and Assist. Prof. Dr. Volkan Demir
}

Editorial Committee (January 2021)

\begin{abstract}
Assoc. Prof. Dr. Abdullah Aksu (TR), Assit. Prof. Dr. Uğur Algancı (TR), Prof. Dr. Bedri Alpar (TR), Assoc. Prof. Dr. Aslı Aslan (US), Prof. Dr. Levent Bat (TR), Prof. Dr. Paul Bates (UK), İrșad Bayırhan (TR), Prof. Dr. Bülent Bayram (TR), Prof. Dr. Luis M. Botana (ES), Prof. Dr. Nuray Çağlar (TR), Prof. Dr. Sukanta Dash (IN), Dr. Soofia T. Elias (UK), Prof. Dr. A. Evren Erginal (TR), Assoc. Prof. Dr. Cüneyt Erenoğlu (TR), Dr. Dieter Fritsch (DE), Prof. Dr. Çiğdem Göksel (TR), Prof.Dr. Lena Halounova (CZ), Prof. Dr. Manik Kalubarme (IN), Dr. Hakan Kaya (TR), Assist. Prof. Dr. Serkan Kükrer (TR), Assoc. Prof. Dr. Maged Marghany (MY), Prof. Dr. Michael Meadows (ZA), Prof. Dr. Nebiye Musaoğlu (TR), Prof. Dr. Masafumi Nakagawa (JP), Prof. Dr. Hasan Özdemir (TR), Prof. Dr. Chryssy Potsiou (GR), Prof. Dr. Erol Sarı (TR), Prof. Dr. Maria Paradiso (IT), Prof. Dr. Petros Patias (GR), Prof. Dr. Elif Sertel (TR), Prof. Dr. Nüket Sivri (TR), Prof. Dr. Füsun Balık Şanlı (TR), Prof. Dr. Uğur Şanlı (TR), Duygu Ülker (TR), Prof. Dr. Seyfettin Taş (TR), Assoc. Prof. Dr. Ömer Suat Taşkın (TR), Assist. Prof. Dr. Tuba Ünsal (TR), Dr. Manousos Valyrakis (UK), Dr. İnese Varna (LV), Dr. Petra Visser (NL), Prof. Dr. Selma Ünlü (TR), Assoc. Prof. Dr. Oral Yağcı (TR), Prof. Dr. Murat Yakar (TR), Assoc. Prof. Dr. İ. Noyan Yılmaz (AU); Assit. Prof. Dr. Sibel Zeki (TR)
\end{abstract}

Abstracting and Indexing: TR DIZIN, DOAJ, Index Copernicus, OAJI, Scientific Indexing Services, International Scientific Indexing, Journal Factor, Google Scholar, Ulrich's Periodicals Directory, WorldCat, DRJI, ResearchBib, SOBIAD 


\title{
Soil Moisture Estimation using Sentinel-1 SAR data and Land Surface Temperature in Panchmahal district, Gujarat State
}

\author{
Sachin Sutariya ${ }^{1} *$, iD Ankur Hirapara ${ }^{1}$, (D) Momin Meherbanali ${ }^{1}$, (D) M.K. Tiwari ${ }^{1}$, \\ Vijay Singh ${ }^{2}$, iD Manik H. Kalubarme ${ }^{2}$
}

${ }^{1}$ Anand Agricultural University, College of Agricultural Engineering and Technology, Department of Irrigation and Drainage Engineering, Godhra, Gujarat, India

${ }^{2}$ Ministry of Electronics \& Information Technology (MEITY), Bhaskaracharya Institute for Space Applications and Geo-informatics (BISAG-N), India

Corresponding Author: S. Sutariya

Received: 07 Agu 2020

E-mail: sachinsutariya1010@gmail.com

Accepted: 25 Nov 2020

How to cite: Sutariya et al., (2021 Soil Moisture Estimation using Sentinel-1 SAR data and Land Surface Temperature in Panchmahal district, Gujarat State, International Journal of Environment and Geoinformatics (IJEGEO), 8(1):065-077. doi: 10.30897/ijegeo.777434

\begin{abstract}
This paper presents the potential for soil moisture (SM) retrieval using Sentinel-1 C-band Synthetic Aperture Radar (SAR) data acquired in Interferometric Wide Swath (IW) mode along with Land Surface Temperature (LST) estimated from analysis of LANDSAT-8 digital thermal data. In this study Sentinel-1 data acquired on 27 February 2020 was downloaded from Copernicus website and LANDSAT-8 OLI data acquired on 24 February 2020 from the website https://earthexplorer.usgs.gov/.The soil samples were collected from 70 test fields in different villages of three talukas for estimating soil moisture content using the gravimetric method. The Sentinel-1 SAR microwave data was analysed using open source tools of Sentinel Application Platform (SNAP) software for estimation of backscattering coefficient. Land surface temperature estimated using Landsat- 8 thermal data. The Landsat8, Thermal infrared sensor Band-10 data and operational land imager Band- 4 and Band-5 data were used in estimating LST. The Soil Moisture Index (SMI) for all field test sites was computed using the LST values. The regression analysis using $\sigma 0 \mathrm{VV}$ and $\sigma 0 \mathrm{VH}$ polarization with soil moisture indicated that $\sigma 0 \mathrm{VV}$ polarization was more sensitive to soil moisture content as compared to $\sigma 0 \mathrm{VH}$ polarization. The multiple regression analysis using field measured soil moisture (MS \%) as dependent variable, and $\sigma 0 \mathrm{VV}$ and SMI as independent variable was carried which resulted in the coefficient of determination (R2) of $0.788,0.777$ and 0.778 for Godhra, Goghamba and Kalol talukas, respectively. These linear regression equations were used to compute the predicted soil moisture in three talukas.
\end{abstract}

Keywords: Analysis Soil Moisture, Sentinel-1 SAR data, LST, SMI, Backscattering coefficient, LANDSAT 8 OLI, TIRS data Introduction temporal variations in soil moisture is great importance for ecological balance.

The Sentinel-1, a polar orbiting satellite system mission is a part of the Global Monitoring for Environment and Security (GMES) program of the European Space Agency (ESA) and the European Commission (EC) and is intended to provide continuous global all weather, day and night radar imaging in support of GMES applications (Drusch et al., 2012). Soil moisture content plays a key role in the crop production as it acts as a nutrient and serves as a solvent for other nutrients such as sodium, potassium, carbon, and nitrogen. It makes a significant impact on plant growth, percolation, and evaporation, microbiological decomposition of the soil organic matter. For many applications in hydrology, horticulture, geotechnical, agriculture and meteorology moisture content on surface of the soil is an important parameter (Ansari and Deshmukh, 2017). In agriculture point of view, soil moisture information is essential for many applications like plant stress, plant turgidity, irrigation scheduling and improving crop yield. The soil moisture affects the amount of water available for vegetation growth (Bezerra, et al., 2013). Soil moisture has a vigorous structure and thus, monitoring spatial and

\section{Microwave Remote Sensing for Soil Moisture estimation}

Microwave remote sensing, both active and passive, has already revealed its potential in soil moisture retrieval independent of weather conditions. This capacity is due to the fact that microwave signals are influenced by dielectric properties (and thus the water content) of the soils (Wang, 1980). There are many studies on estimating soil moisture using both passive and active remote sensing satellites. Active microwave remote sensing systems have been recently preferred in soil moisture studies because of the remarkable penetrating capabilities of radar signal into the surface. In SAR images, the sigma naught $(\sigma 0)$ which is considered as backscattering coefficient, presents the amplitude of the signal returned from target to SAR antenna that is influenced by the soil surface characteristics which is linked to the soil moisture and soil surface roughness (Mirsoleimani, et al., 2019). Retrieval of soil surface parameters from SAR data normally can be realized using the backscattering model that presents the relation between the target parameters (soil moisture and 
roughness) and the SAR sensor configurations such as incidence angle, polarization, and frequency (Sahebi et al., 2002). The backscattered SAR signal is affected strongly from soil moisture and surface roughness on bare soil (Ulaby, Moore, and Fung, 1986; Zribi et al., 2007). For bare soils, different theoretical and empirical approaches have been developed and many approaches assumed that there is a linear behaviour between surface soil moisture and SAR backscattering coefficient (sigmanought:б0) (Esetlili and Kurucu, 2016; Esetlili et al., 2018; Gao, Zribi, Escorihuela, and Baghdadi, 2017; Zribi, Baghdadi, Holah, and Fafin, 2005). The relative SMC ranges from zero in dry soil to unity (or 100\%) in a completely saturated soil. Wagner et al., 1999a, b, developed a SMC retrieval algorithm for the ERS scatterometer. ERS backscattering is described in terms of empirical backscatter parameters and the relative surface SMC according to $\sigma 0(\theta, \mathrm{t})=\sigma 0$ dry $(\theta, \mathrm{t})+$ $\mathrm{S}(\mathrm{t}) \mathrm{ms}(\mathrm{t})$, where $\theta$ is the local incidence angle, $\mathrm{t}$ is the time, $\sigma 0$ dry is the backscattering coefficient observed under completely dry soil conditions in decibels, and $\mathrm{S}$ is the sensitivity in decibels of the $\sigma 0$ to changes in soil moisture.

\section{Water Cloud Model (WCM) to estimate the soil moisture}

A semi-empirical model i.e. water cloud model (WCM) was used to estimate the SM in the area of Varanasi district, India using C- band Sentinel -1A SAR data. The potential of inversion scheme was checked using three types of vegetation descriptors (LWAI, LAI and fveg). WCM parameterization was done using non-linear least square optimization algorithm and the results indicated high correlation between the estimated SM with the insitu observation $(\mathrm{R} 2=0.847, \mathrm{RMSE}=3.23)$. Landsat- 8 derived vegetation descriptor was found better in WCM for the estimation of SM more accurately (Yadav, et al., 2019; Küçükmatçı and Avdan, 2019). The prospects of semi-empirical Water Cloud Model (WCM) to estimate the soil moisture content was tested in a fragmented agricultural region for different time periods. The concurrent satellite data obtained from Sentinel-1A and Landsat 8 were utilized to supply the inputs for inversion modelling based on the Levenberg-Marquardt approach. The current research introduced 'virtual Normalized Difference Vegetation Index' concept to refine the WCM and yielded reliable soil moisture output for supplementing the anchor pixel selection process. The research results indicated that the anchor pixel selection with and without soil moisture criterion has a significant impact on actual evapotranspiration estimation. The research also explores the scope of the synergetic use of optical and Synthetic Aperture Radar (SAR) inputs in SEBAL (Prakash Mohan et al, 2019).

Sentinel-1 and Landsat-8 data were used to retrieve soil moisture from top soil surface $(0-5 \mathrm{~cm}$ depth) at agricultural land (area under wheat crop). Water Cloud Model (WCM) was used for removal of vegetation influence ( $r$-veg), total backscattering coefficient ( $r$ total) and Normalized Difference Vegetation Index (NDVI) were used to simulate backscattering from soil ( $\mathrm{r}$ soil. Further, modelled soil moisture was evaluated using in situ soil moisture measurements and a Time Domain Reflectometer during Sentinel-1 overpass (24 January, 25 February and 13 March 2018). Statistical tests showed that an integrated approach has potential to improve soil moisture estimates over the vegetated/cropped area for agricultural and hydrological studies (Rawat et al. 2019).

\section{Multi-sensor fusion for soil moisture retrieval}

In recent few years, there has been growing interest in multi-sensor fusion for retrieving soil moisture. Synthetic aperture radar (SAR) and optic data fusion is one of the most foremost used approaches (Gao et al., 2017 and Prakash et al., 2012). An approach for retrieval of soil moisture content (SMC) by coupling single polarization $\mathrm{C}$ band synthetic aperture radar (SAR) and optical data at the plot scale in vegetated areas was presented by Reza Attarzadeh, 2018.The study was carried out at five different sites with dominant vegetation cover located in Kenya. Within the initial state of the study, different features are extracted from single polarization mode (VV polarization) SAR and optical data. A complicated advance state of the art machine learning regression approach, the support vector regression (SVR) technique, is used to retrieve soil moisture. This paper takes a new look at soil moisture retrieval in vegetated areas considering the needs of practical applications. Using optical, thermal infrared (TIR), and microwave (MW) sensors different retrieval of soil moisture approaches have been developed (Barrett et al., 2013). Optical sensors in the thermal spectrum are able to identify temperature differences, which can be related to surface soil moisture. Microwave soil moisture estimations are based on the strong contrast between the dielectric properties of water $(\approx 80)$ and dry soil (<5) (Zhuo and Han, 2016). Surface SMC can be estimated based on Normalized Difference Vegetation Index (NDVI) and LST. Petropoulos et al., (2009) described this LST/NDVI relationship as a linear relationship with the SMC. Zeng et al., 2004 proposed a method to retrieve SMC based on the integration of LST and NDVI called Triangle method. LST is determined from thermal emission, and NDVI is estimated based on surface reflectance of red and the near infrared portions of the electromagnetic spectrum, so these methods sometimes are termed as optical, thermal infrared remote sensing (Amato et al., 2015; Rahimzadeh-Bajgiran et al., 2013; Traore et al., 2020).

\section{Thermal Remote Sensing for Soil Moisture Estimation}

For alternatively use to microwave remote sensing approaches, thermal remote sensing has also been extensively used to monitor soil moisture and its related variables (Amazirh et al., 2018). The land surface temperature (LST) derived from (Avdan and Jovanovska, 2016; Şekertekin et al., 2016; İncekara et al., 2017; Çelik et al., 2019; Sekertekin, and Bonafoni, S. 2020) the use of the LANDSAT 8 thermal infrared sensor Band 10 data and operational land imager Band 4 and Band 5 data. To understand the interaction between SAR signals and the surface many models have been developed. Different theoretical and empirical 
approaches have been developed for estimating soil moisture and many approaches assumed that there is a linear correlation between surface soil moisture and SAR backscattering coefficient $(\sigma 0)$ (Amazirh et al., 2018; Mirsoleimani et al., 2019; Şekertekin et al., 2018; Paloscia et al., 2013 and Esetlili and Kurucu, 2016).

The soil moisture distribution was estimated using Cband Synthetic Aperture Radar (SAR) data in an agricultural region in Bergama, a district of İzmir city (Şekertekin et al, 2016). In-situ soil moisture measurements were carried out in 20 test fields simultaneously with SAR data acquisition. The effects of soil moisture and local incidence angle on backscattering coefficient were analysed using these acquisition data, and then a multiple regression analysis was performed to generate an empirical model. The proposed model was evaluated using statistical metrics namely coefficient of determination (R2) and Root Mean Square Error (RMSE), and the results were 0.84 and $2.46 \%$, respectively. Mohamed et al, 2019, carried out a study was in the east of Nile Delta of Egypt to predict soil moisture content using optical remote sensing data and Synthetic Aperture Radar (SAR) Sentinel-1 data. A number of 100 surface soil samples were collected to represent different soil types in the study area. Soil Moisture Index (SMI) is assessed based on thermal remote sensing data as Land Surface Temperature (LST) besides, Sentinel-1 data. The results showed a high correlation between SMC and SMI, coefficient of determination (R2) reached 0.81 between actual soil moisture and SMI. Furthermore, a significant correlation was also shown by Sentinel-1 data, with R2 of 0.83 between actual soil moisture content and backscattering coefficient $(\mathrm{dB})$.

The main objective of this study is to estimate and map soil moisture distribution using Sentinel-1 C-band SAR data in combination with LST estimated from Landsat-8 OLI data.

\section{Materials and Methods Study Area}

Panchmahal District is situated in the Northern side of Gujarat. It lies between the parallels of latitude $20.34^{\circ}$ and $23.30^{\circ} \mathrm{N}$ and the meridians of longitude $73.15^{\circ}$ and $74.03^{\circ} \mathrm{E}$. The districts rich in water resources and is drained by seven important rivers, viz., the Mahi, the Goma, the Kun, the Panam, the Karad, the Kali and the Meshri. It is further divided into seven talukas such as Godhra, Halol, Kalol, Jambughoda, Shahera, Morva Hadaf and Ghoghamba. From this seven talukas Godhra, Ghoghamba and Kalol were selected for this study (Figure 1).

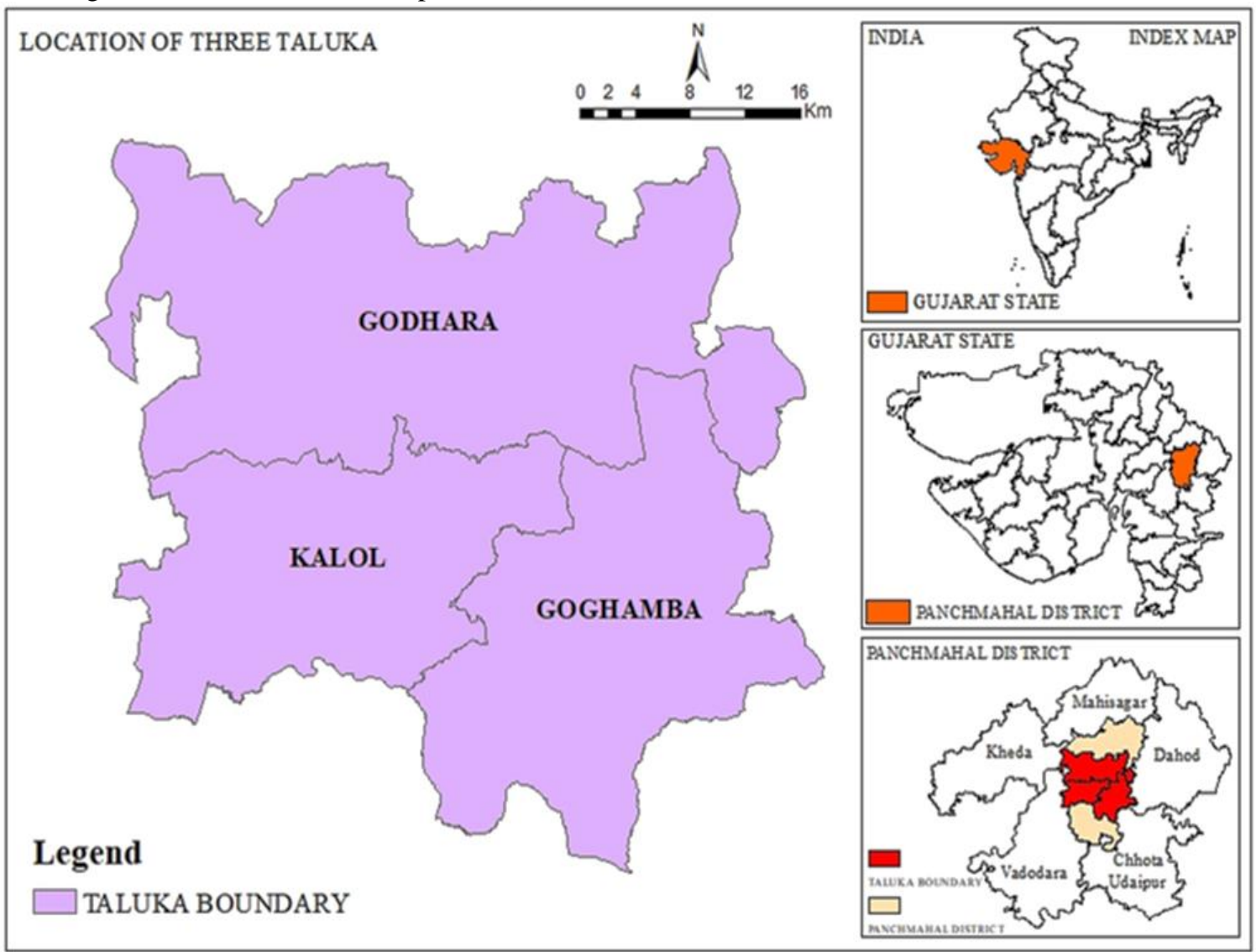

Figure-1: Location map of Study Area in Panchmahal District, Gujarat State

\section{Remote Sensing Satellite Data Used}

The LANDSAT-8 OLI digital data was downloaded from the United States Geological survey official website, NASA, website of USGS. The Sentinel-1 SAR data was downloaded from the Copernicus website. Landsat- 8 is an American Earth observation satellite launched on February 11, 2013. It ensures the continued 
acquisition and availability of Landsat data utilizing a two-sensor payload, the Operational Land Imager (OLI) and the Thermal Infrared Sensor (TIRS). These two instruments collect data for nine shortwave bands and two long wave thermal bands (Department of the Interior U.S. Geological Survey, 2016). In this study, Landsat-8 satellite imagery acquired on 24-Feb-2020 (Path/Row: 148/44) was downloaded from USGS website (Figure2). Sentinel-1 satellite provides C-band images in both singular and dual polarization within 12 days of repeat cycle. It can acquire images in three acquisition modes as Strip map (SM), Interferometric Wide Swath (IW), Extra Wide Swath (EW) and Wave (WV) with different processing levels (Drusch et al., 2012). In this study, Level-1, GRD product with VV and VH polarization with the acquisition mode of IW was acquired for analysis. The details of Landsat-8 OLI and Sentinel-1 SAR digital data are given in Table-1.

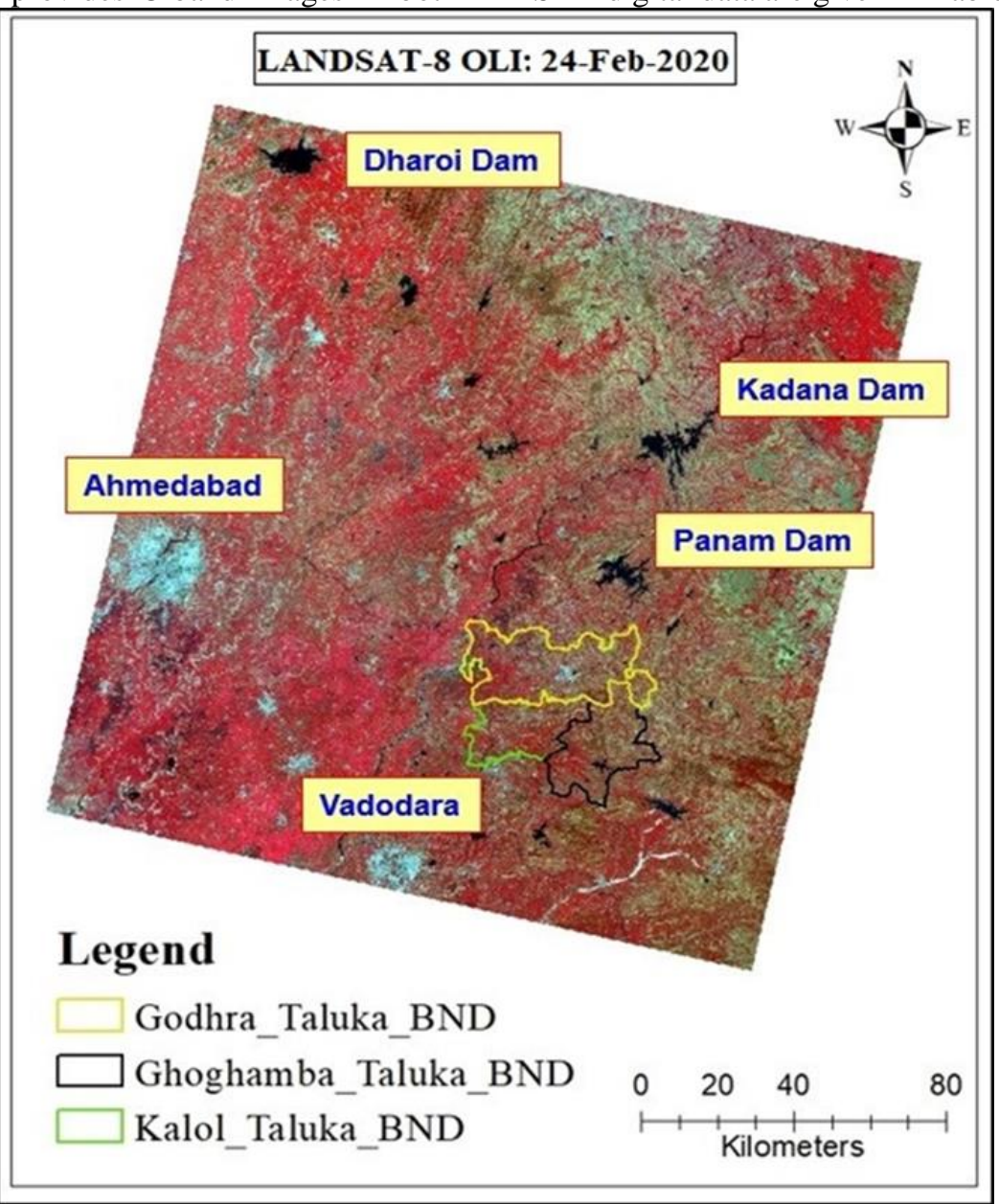

Figure-2: Landsat-8 OLI image covering study area with Taluka boundaries.

Table-1: Specifications of Satellite Data used

\begin{tabular}{|c|c|c|}
\hline Satellite/Sensor & Speci & tions \\
\hline \multirow{5}{*}{$\begin{array}{c}\text { Landsat-8 OLI \& } \\
\text { TIRS }\end{array}$} & $\begin{array}{l}\text { Acquisition } \\
\text { date }\end{array}$ & 24-FEB-2020 \\
\hline & Spatial & $30 \mathrm{~m}(\mathrm{OLI}) \&$ \\
\hline & Resolution (m) & $100 \mathrm{~m}$ (TIRS) \\
\hline & Path / Row & $148 / 44$ \\
\hline & Data Product & Collection-1 \\
\hline \multirow{8}{*}{ Sentinel-1 SAR } & $\begin{array}{c}\text { Acquisition } \\
\text { date }\end{array}$ & 27-FEB-2020 \\
\hline & $\begin{array}{l}\text { Acquisition } \\
\text { orbit }\end{array}$ & Descending \\
\hline & Imaging & C-band (5.4 \\
\hline & frequency & $\mathrm{GHz})$ \\
\hline & $\begin{array}{c}\text { Spatial } \\
\text { Resolution (m) }\end{array}$ & 10 \\
\hline & Imaging Mode & IW \\
\hline & Polarization & VV-VH \\
\hline & Data product & Level-1 GRD \\
\hline
\end{tabular}

\section{Soil Sample Collection in the Field}

Five villages were selected randomly in each taluka and in each village five soil sample collection sites were identified on the maps created in GIS. The soil samples were collected near synchronous with respect to the Sentinel-1 acquisition date. It was observed that there was no crop or vegetation cover in the test fields. The surface roughness, which is another important variable which affecting backscattering coefficient, was ignored because it was not so high for the test sites. Also, the selected fields for soil sample collection were not irrigated or there were no rains in the study area. The soil samples were collected using the soil auger from the depth of $10 \mathrm{~cm}$ and these soil samples were packed in air tight polythene bags. These collected soil samples were brought to laboratory and put into the aluminium containers. A total number of 70-soil samples were collected from the identified sample points in different villages of Godhra, Ghoghamba and Kalol talukas (Figure-3). The collected soil samples were oven-dried in the laboratory. The process of soil sample collection in the field and drying them in the hot-air oven is given in Figure-4. 


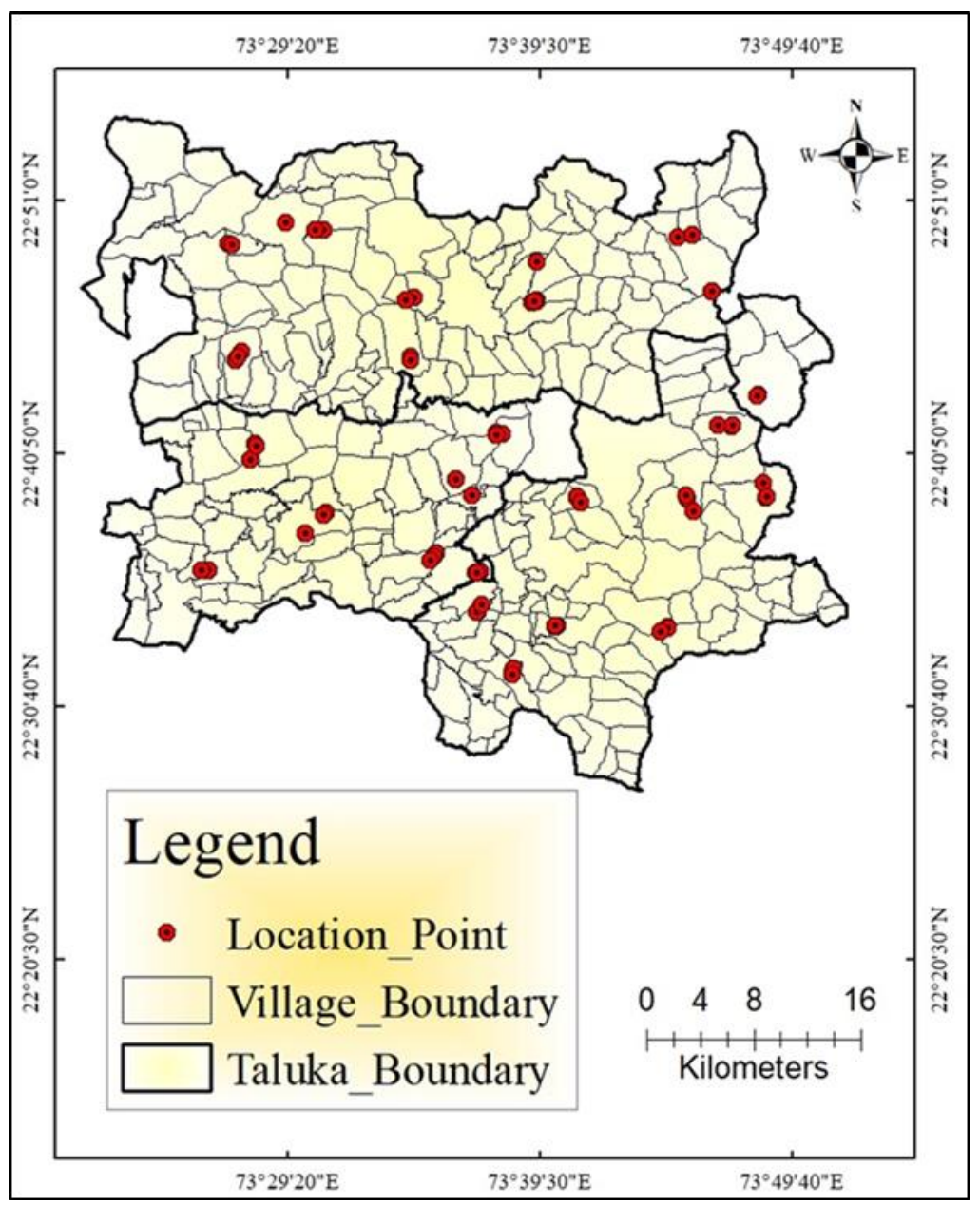

Figure-3: Locations of Soil Sample points in different villages.
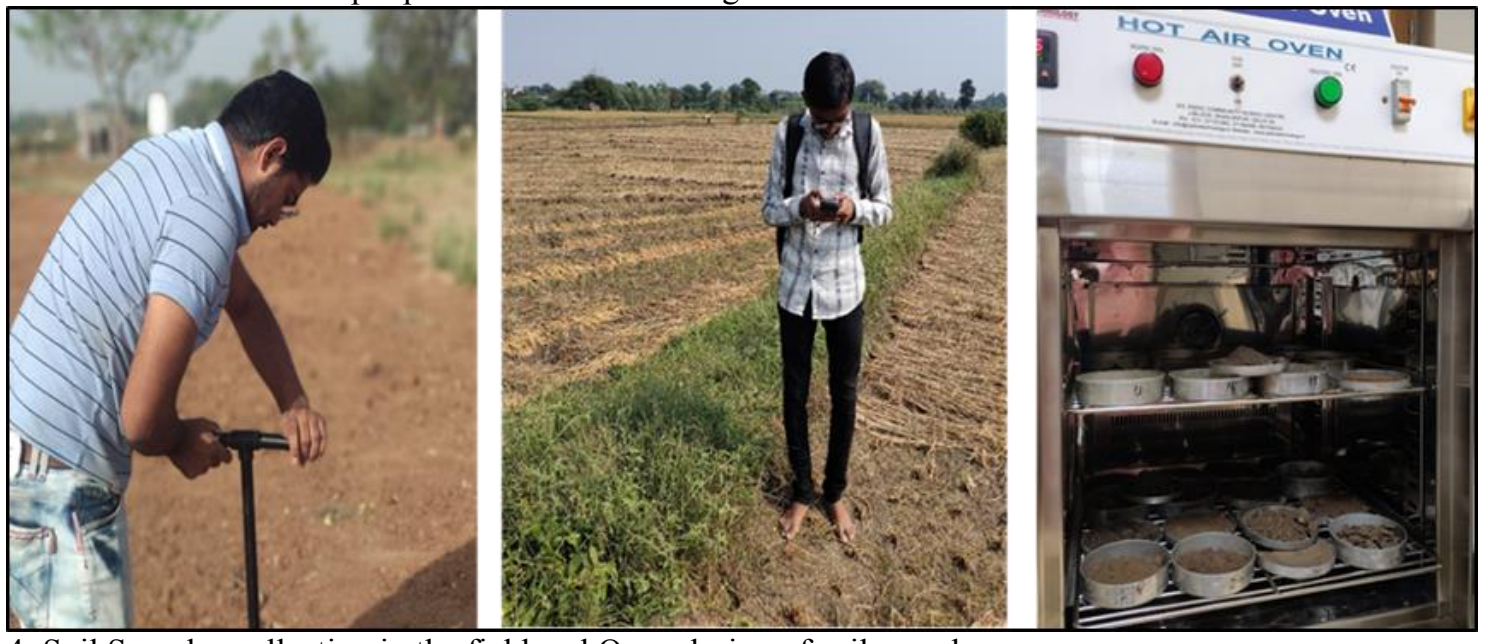

Figure-4: Soil Samples collection in the field and Oven drying of soil samples.

\section{Soil Moisture Determination using Field Data}

In recent decades, many different methods are available to determine soil moisture content. Determining soil moisture is generally considered in two groups, namely direct and indirect methods. In direct methods, the soil moisture is calculated relating to the difference between the weights of the soil sample before and after drying. In indirect methods, soil moisture content is determined by sensors and using other variables which affect the moisture content and it depends upon the device accuracy. So, the gravimetric method (direct method) is more authentic and provides accurate soil moisture than the indirect method such as dielectric method, tensiometric method etc. In this study, a gravimetric soil moisture determination method was used (Myhre and Shih, 1990; Bittelli, 2011). In the gravimetric method firstly the soil samples are collected from the field and weighted, then placed in the hot-air oven and dried at $105^{\circ} \mathrm{C}$ temperature for 24 hours (Almaw et. al., 2018).

After complete drying the samples are weighted again to obtain dry weights, and soil moisture is estimated using the following equation (1): 
Soil Moisture $(\%)=\left(M_{w} / M_{s}\right) \times 100$

1

Where, Mw is mass of water and Ms is the mass of dry soil.

$\mathrm{M}_{\mathrm{w}}=$ (weight of wet soil + can $)-$ (weight of oven dry soil + can)

$\mathrm{M}_{\mathrm{s}}=$ (weight of oven dry soil + can $)-$ weight of can

The average mean values for each plot were computed from all the soil samples within each plot. The range of the soil moisture values are between 5 to 15,5 to 17 and 3 to 13 vol. \%, for Godhra, Goghamba and Kalol Talukas, respectively.

\section{Land Surface Temperature (LST) Estimation}

The Landsat-8 OLI and TIRS digital data was analyzed for estimation of Land Surface Temperature (LST) of the study area. Thermal infrared sensor Band-10 data and operational land imager Band- 4 and Band-5 data were used in estimating LST and characteristic of these bands (Department of the Interior U.S. Geological Survey, 2016) shown in Table-2.

From the Landsat- 8 digital data; Red, NIR and TIRS bands were used for calculation of LST and steps described by Avdan and Jovanovska, 2016 were followed in this study. The major steps are:

i) Converting digital numbers (DN) to top-of-theatmosphere (TOA) radiance values

ii) Conversion of radiance to at-sensor brightness temperature,

iii) Calculation of Normalized Difference Vegetation Index (NDVI),

iv) Computation of Proportion of Vegetation (PV),

v) Estimating the surface emissivity using an empirical relationship based on the NDVI,

vi) Calculating LST using the simplified Plank's law. The flow chart of LST estimation is given in Figure-5. The details of each step are described in following sections:

Table-2: Spectral Band characteristics of LANDSAT-8

\begin{tabular}{ccccc}
\hline Band & Resolution $(\mathbf{m})$ & Spectral Band & Wavelength $(\boldsymbol{\mu m})$ & $\begin{array}{c}\text { Solar irradiance } \\
\left(\mathbf{W} /\left(\mathbf{m}^{2} \boldsymbol{\mu m}\right)\right.\end{array}$ \\
\hline 4 & 30 & Red & $0.630-0.680$ & 1574 \\
5 & 30 & Near Infrared & $0.845-0.885$ & 955 \\
10 & 100 & Longwave Infrared & $10.60-11.19$ & -- \\
\hline
\end{tabular}

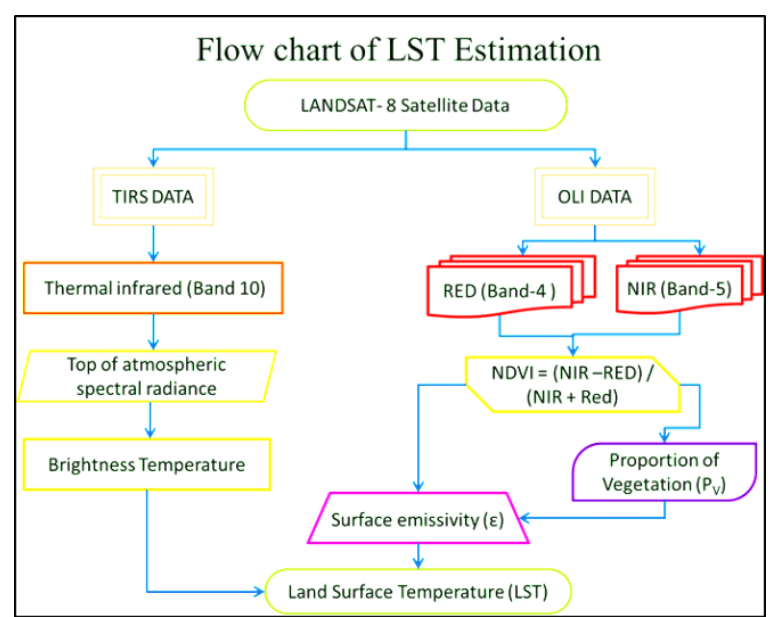

Figure-5: Flow chart for LST estimation using Landsat8 data

i) Top of atmospheric spectral radiance

In the first step of LST estimation, band 10 from Landsat-8 OLI data has been used for estimation of top of atmospheric (TOA) spectral radiance (L $\lambda$ ):

$$
L \lambda=M_{l} \times Q_{c a l}+A_{l}-Q_{i}
$$

Where, $\mathrm{L} \lambda=$ Top of atmospheric spectral radiance, $\mathrm{M}_{\mathrm{l}}=$ Band-specific multiplicative rescaling factor, $\mathrm{Q}_{\text {cal }}=$ Band 10 image, $A_{1}=$ and-specific additive rescaling factor, $\mathrm{Q}_{\mathrm{i}}=$ correction for Band 10 .

ii) Conversion of Radiance to at Sensor Temperature Conversion of radiance to at-sensor temperature is carried out to estimate the brightness temperature using the thermal constants which are given in Landsat-8 metadata file:

$$
B T=\frac{K_{2}}{\ln \left(K_{1} / L \lambda\right)+1}-273.15
$$

Where, $\mathrm{BT}=$ Brightness temperature, $\mathrm{K}_{1}$ and $\mathrm{K}_{2}$ $=$ Band-specific thermal constants, $\mathrm{L} \lambda=$ Top of atmospheric spectral radiance

iii) Calculation of Normalized Difference Vegetation Index (NDVI) for Emissivity Correction

The amount of vegetation present can be estimated using NDVI and it can also be used to infer general vegetation condition (Weng et al., 2004). The NDVI is required for computing the Proportion of Vegetation $\left(\mathrm{P}_{\mathrm{V}}\right)$ which is highly related with NDVI, and emissivity ( $\varepsilon$ ) should be calculated, which is related to the $\mathrm{P}_{\mathrm{V}}$ :

$$
N D V I=\frac{N I R(\text { band } 5)-R(\text { band } 4)}{N I R(\text { band })+R(\text { band } 4)}
$$

Where, NDVI=Normalized Difference Vegetation Index, NIR = Near-infrared band (Band-5), $R=$ Red band (Band-4)

iv) Computation of Proportion of Vegetation (PV)

$$
P_{v}=\left(\frac{N D V I-N D V I_{S}}{N D V I_{v}-N D V I_{s}}\right)^{2}
$$

Where, $\mathrm{P}_{\mathrm{v}}=$ Proportion of Vegetation, NDVI=Normal Difference Vegetation Index, $\mathrm{NDVI}_{\mathrm{V}}=0.5, \mathrm{NDVI}_{\mathrm{S}}=0.2$. v) Estimating the surface emissivity (LSE) using an empirical relationship based on the NDVI 
For calculating LSE in the model when the NDVI value is less than 0 , it is classified as water, and the emissivity value 0.991 is considered. For NDVI values between 0 to 0.2 , it is classified as the land is covered with soil and there is no vegetation, and the emissivity value 0.996 is considered and the NDVI value is greater than 0.5 , it is classified as land covered with vegetation and the emissivity value of 0.973 is considered. The NDVI values between 0.2 and 0.5 are classified as mixtures of soil and vegetation and the emissivity can be calculated follows,

$$
\varepsilon_{\lambda}=\varepsilon_{v \lambda} P_{v}+\varepsilon_{s \lambda}\left(1-P_{v}\right)+C_{\lambda}
$$

Where, $\varepsilon_{\lambda}=$ Land Surface Emissivity, $\mathrm{P}_{\mathrm{v}}=$ Proportion of Vegetation, $\varepsilon_{\mathrm{v} \lambda}=0.973, \varepsilon_{\mathrm{s} \lambda}=0.996, \quad \mathrm{C}_{\lambda}=$ Surface roughness $(0.005)$

vi) Land surface temperature Computation

Land surface temperature (LST) is computed using the following equation:

$$
T_{s}=\frac{B T}{\left\{1+\left[\frac{\lambda B T}{\rho}\right] \ln \varepsilon_{\lambda}\right\}}
$$

Where, $\mathrm{T}_{\mathrm{s}}=$ land surface temperature $\left({ }^{\circ} \mathrm{C}\right)$, BT $=$ Brightness temperature, $\varepsilon_{\lambda}=$ Land Surface Emissivity, $\lambda=$ limiting wave length (10.895), $\rho=$ $1.438 \times 10^{-2} \mathrm{~m}$

\section{Soil Moisture Index (SMI) Computation using LST}

The soil moisture index (SMI) is defined as the proportion of the difference between the current soil moisture and the permanent wilting point to the field capacity and the residual soil moisture. The index values range from 0 to 1 with 0 indicating extreme dry conditions and 1 indicating extreme wet conditions (Chandrasekar, 2016). The SMI has been retrieved directly according to (Moawad, 2012) using LST as follows:

$$
\text { SMI }=\left(\mathbf{L S T}_{\max }-\mathbf{L S T}\right) /\left(\mathbf{L S T}_{\max }-\mathbf{L S T}_{\text {min }}\right)
$$

Where: SMI is Soil Moisture Index, $\mathrm{LST}_{\text {max }}, \mathrm{LST}_{\min }$, LST are the maximum, minimum and value of the retrieved LST respectively. The SMI for all the sample plots in three talukas was computed and the range of SMI values were between 0.148 to $0.868 ; 0.167$ to 0.857 ; and 0.115 to 0.889 for Godhra, Goghamba and Kalol Talukas, respectively

\section{Sentinel-1 Image Pre-processing}

Sentinel-1 provides data with a spatial resolution of 10 $\mathrm{m}$ and a temporal resolution of 12 days, in both VV and $\mathrm{VH}$ polarizations. In this present study, VV polarization data were used to estimate the soil moisture. Previous studies have shown that $\mathrm{VH}$ data has only a limited potential for the estimation of soil moisture, in particular as a consequence of its high sensitivity to volume scattering, which depends strongly on the geometrical alignment and characteristics of the vegetation (Karjalainen, et 1., 2004; Chauhan, and Srivastava, 2016). ESA announced some steps to be performed with open source tools of Sentinel Application Platform (SNAP) software for determining backscattering coefficient $\left(\sigma^{0}\right)$. The steps of this analysis included: apply orbit file, thermal noise removal, border noise removal, radiometric calibration, speckle filtering, range doppler terrain correction and Conversion to dB (Filipponi, 2019). After applying all these steps, final backscattering coefficient image was generated from the high-resolution Level-1 Ground Range Detected (GRD) product with a spatial resolution of $10 \mathrm{~m} \times 10 \mathrm{~m}$.

For Sentinel-1 SAR data preprocessing the Sentinel Application Platform (SNAP) software was utilized to perform radiometric and geometric corrections. The DN values of raw Sentinel-1 data were first converted to $\sigma 0$ using radiometric calibration. Then, the calibrated Sentinel-1 data was georeferenced using the terrain correction algorithm. In the second step, the mean values of $\sigma 0$ are extracted for each field sample. For this, the selected fields were identified on image based on their geographic coordinate. Then the boarder of each field was determined and the average of $\sigma 0$ for internal pixels was calculated (Mirsoleimani, et al., 2019). The methodology flow-chart adopted for data analysis is given in Figure-6.

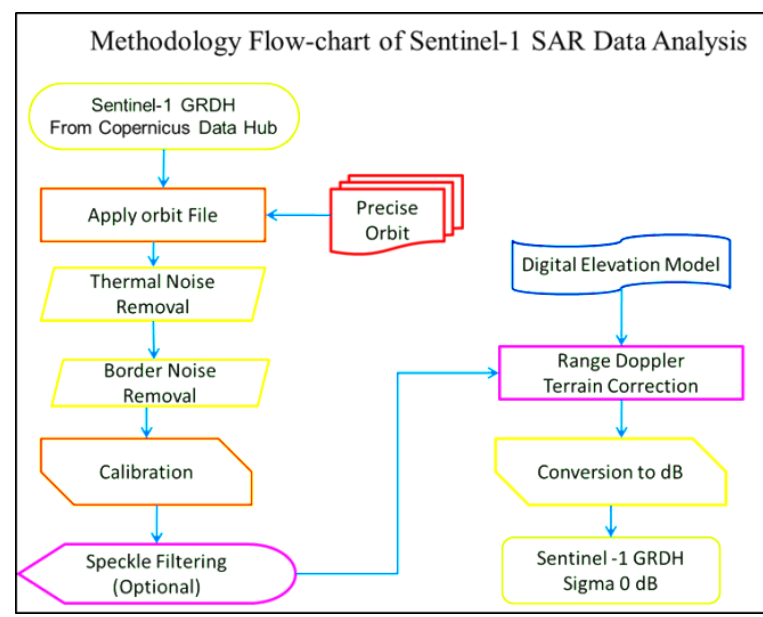

Figure-6: Methodology flow chart of Sentinel-1 SAR data analysis

\section{Pre- processing (Calibration) of Sentinel-1 Product}

The main task of calibration is to derive the calibration constant by measurements of targets with exactly known backscatter coefficients. The methodology for performing the data analysis of backscatter data (Filipponi, 2019) as is follows:

\section{i) Apply Orbit File}

The orbit state vectors provided in the metadata of a SAR product are generally not completely accurate and can be refined with the precise orbit files which are available days-to-weeks after the generation of the product. Based on accurate satellite position and velocity information, the orbit state vectors in the abstract metadata of the product are updated. For 
Sentinel-1, resituated orbit files and precise orbit files may be applied. Precise orbits are produced a few weeks after acquisition.

\section{ii) Thermal Noise Removal}

Thermal noise removal reduces noise effects in the inter-sub-swath texture, in particular, normalizing the backscatter signal within the entire Sentinel-1 scene and resulting in reduced discontinuities between subswaths for scenes in multi-swath acquisition modes. It can be applied to Sentinel-1 Level-1 SLC products as well as Level-1 GRD products which have not already been corrected. The operator can also remove this correction based on the product annotations (i.e. to reintroduce the noise signal that was removed). Accordingly, to allow for re-application of the correction product annotations will be updated. The Level-1 products provide a noise LUT for each data.

iii) Border Noise Removal

While generating level-1 products, it is necessary to correct the sampling start time in order to compensate for the change of the Earth's curvature. At the same time, azimuth and range compression leads to radiometric artefacts at the image borders. The border noise removal algorithm, available as an operator in SNAP, was designed in order to remove low intensity noise and invalid data on scene edges.

\section{iv) Calibration}

Calibration is the procedure that converts digital pixel values to radio metrically calibrated SAR backscatter. The information required to apply the calibration equation is included within the Sentinel-1 GRD product; specifically, a calibration vector included as an annotation in the product allows simple conversion of image intensity values into sigma nought values. The calibration reverses the scaling factor applied during level-1 product generation, and applies a constant offset and a range-dependent gain, including the absolute calibration constant.

\section{v) Conversion to $\mathrm{dB}$}

As a last step of the pre-processing workflow, the unit less backscatter coefficient is converted to $\mathrm{dB}$ using a logarithmic transformation, to $\mathrm{dB}$ as $10 * \log _{10} \sigma_{0}$. The scattering behaviour depends on the physical characteristics of the terrain, primarily the geometry of the terrain elements and their electromagnetic characteristics.

\section{Landsat-8 and Sentinel-1 Satellite data analysis}

In this study, back scattering coefficient $\sigma^{0} \mathrm{vv}(\mathrm{dB})$ and soil moisture index (SMI) is considered as a function of soil moisture as given in Equation -9.

$$
\mathrm{MC}(\%)=\mathrm{X}_{1} * \mathrm{SMI}+\mathrm{X}_{2} * \sigma^{0} \mathrm{vv}(\mathrm{dB})+\mathrm{c}
$$

Where $\sigma^{0}(\mathrm{~dB})$ is backscattering coefficient, and SMI is the Soil Moisture Index. In this multiple regression analysis, $\mathrm{MC}(\%)$ is considered as a dependent variable, whereas $\sigma^{0}(\mathrm{~dB})$ and SMI are independent variables.

\section{Validation of Soil Moisture}

For the validation of the predicted soil moisture, performance indices namely coefficient of determination $\left(\mathrm{R}^{2}\right)$ and standard deviation $(\mathrm{S})$ were utilized. The equation of these performance indices is presented in Equation 10 and 11.

$$
R^{2}=\left[\frac{\sum_{i=1}^{n}\left(O_{i}-\bar{O}\right)\left(P_{i}-\bar{P}\right)}{\sqrt{\sum_{i=1}^{n}\left(O_{i}-\bar{O}\right)^{2} \sum_{i=1}^{n}\left(P_{i}-\bar{P}\right)^{2}}}\right]^{2}
$$

Where $\mathrm{O}_{i}$ and $\mathrm{P}_{i}$ are the observed soil moisture and predicated soil moisture respectively, $\overline{\mathrm{O}}$ and $\overline{\mathrm{P}}$ are the mean values of the observed soil moisture and predicated soil moisture respectively and $\mathrm{n}$ is the number of data sets.

$$
S=\sqrt{\frac{\sum_{i=1}^{n}\left(x_{i}-\bar{x}\right)^{2}}{(n-1)}}
$$

Where, $\mathrm{S}$ is the standard deviation of data set, $\mathrm{x}_{\mathrm{i}}$ is each value in the data set, $\bar{x}$ is the mean of all values in data set and $\mathrm{n}$ is the total number of data sets.

The shape files were created for each test site, and mean LST and mean $\sigma^{0}(\mathrm{~dB})$ values of each sample test site in three talukas were extracted using the shape files in ArcGIS software. The Soil Moisture Index (SMI) values for each sample plots were computed using the LST data. The multiple regression analysis was carried out between back scattering coefficient $\sigma^{0}(\mathrm{~dB}) \&$ and Soil Moisture Index (SMI) with field measured soil moisture values.

\section{Results and Discussion \\ Estimation of Land Surface Temperature from Landsat-8 Satellite Data}

The algorithm was created in ArcGIS for estimating land surface temperature using Landsat- 8 OLI and TIRS data. For estimating LST, the TIRS band-10 was used to estimate brightness temperature and bands-4 (Red) and 5 (NIR) were used for calculating the NDVI. Land surface temperature of Godhra, Goghamba and Kalol talukas of Panchmahal district was estimated using the LANDSAT-8 data of 24-FEB-2020 and the results of one of the talukas i.e. Godhra Taluka is presented in Figure-7 and LST values of major land use classes are given in Table- 3 .

Table-3: Land surface temperature of different land use classes in Godhra taluka

\begin{tabular}{lllll}
\hline Sr. No. & Class & Area (ha) & Mean Temp $\left({ }^{\mathbf{0}} \mathbf{C}\right)$ & Std. Dev \\
\hline 1 & Agriculture & 22263.6 & 25.76 & 1.59 \\
2 & Water-body & 1853.8 & 23.77 & 1.93 \\
3 & Built-up & 43262.8 & 27.33 & 1.72 \\
4 & Waste Land & 9071.5 & 26.91 & 1.91 \\
\hline
\end{tabular}




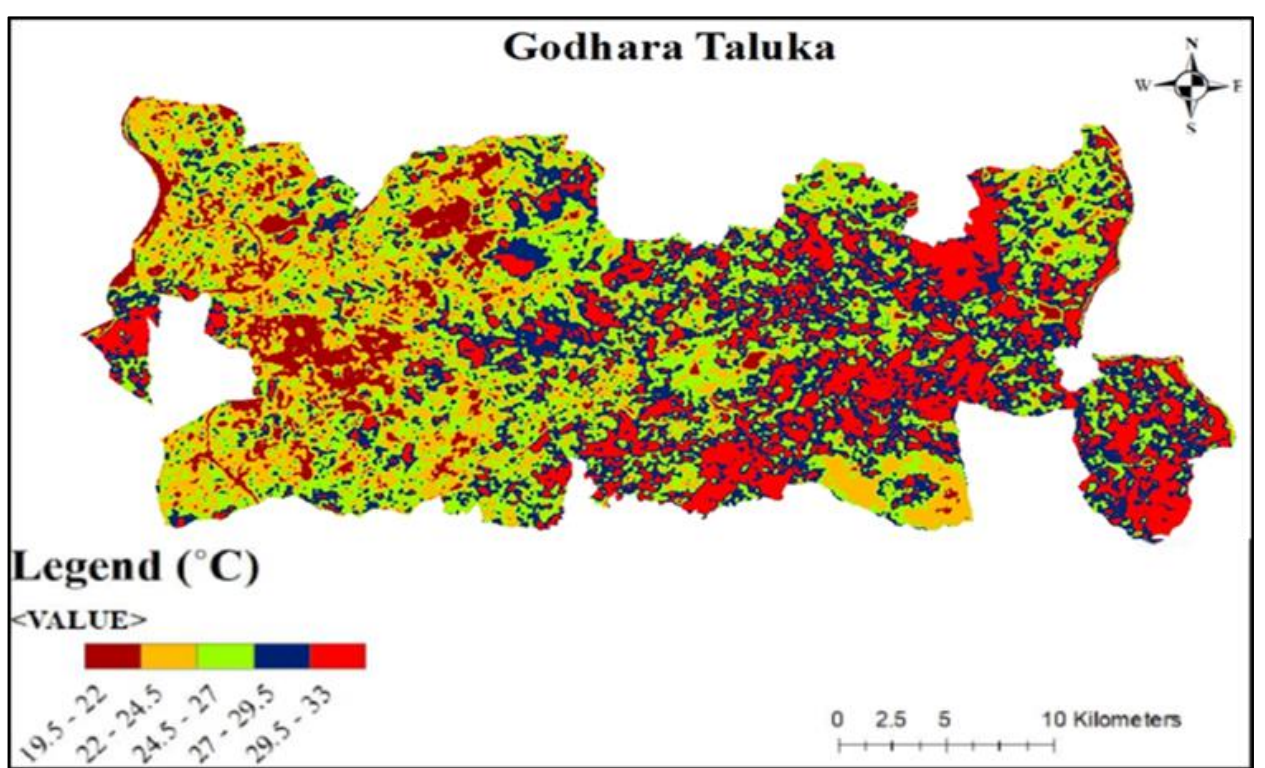

Figure-7: Land Surface Temperature (LST) map of Godhra Taluka

\section{Estimation of Backscattering Coefficient $\boldsymbol{\sigma}_{\mathrm{vv}}^{0}(\mathrm{~dB})$ from Sentinel-1 Satellite Data}

The open source tools of Sentinel Application Platform (SNAP) software was used for determining backscattering coefficient values from Sentinel-1 data. All the steps were described in this software from applying orbit file to conversion to $\mathrm{dB}$ were applied and the backscatter image of $\mathrm{VV}$ and $\mathrm{VH}$ polarization was generated for each $10 \mathrm{~cm} \times 10 \mathrm{~cm}$ grid. The efficiency of single polarization (VV) is better than the cross polarization (VH) of backscatter data for soil moisture estimation. Backscattering coefficient images of Godhra, Goghamba and Kalol talukas were generated using the Sentinel-1 data for the date of 27Feb-2020. The Backscatter Coefficient, $\sigma_{\mathrm{vV}}^{0}(\mathrm{~dB})$ values of major land use classes in Godhra Taluka are given in Table-4.

Table-4: Backscattering coefficient $\sigma_{\mathrm{VV}}^{0}(\mathrm{~dB}) \mathrm{VV}$ of different land use classes for Godhra

\begin{tabular}{ccccc}
\hline Sr. No. & Class & Area (ha) & Mean $\boldsymbol{\sigma}_{\mathbf{v v}}^{\mathbf{0}}(\mathbf{d B})$ & Std. Dev \\
\hline 1 & Agriculture & 22263.6 & -10.21 & 1.81 \\
2 & Water body & 1853.8 & -12.98 & 1.76 \\
3 & Built-up & 43262.4 & -11.00 & 1.66 \\
4 & Waste Land & 9071.5 & -10.93 & 1.85 \\
\hline
\end{tabular}

\section{Linear Regression Analysis}

For estimate the soil moisture content of sample fields in three talukas, the shape files of each field were created and mean LST and mean $\sigma^{0}(\mathrm{~dB})$ values of each test site were extracted using the shape files in ArcGIS software. The datasets of field measured soil moisture (\%) of sample test sites in each village, $\sigma_{\mathrm{VV}}^{0}(\mathrm{~dB})$, and Soil Moisture Index (SMI) generated using LST data were created for three talukas separately. These datasets were used in the multiple regression analysis to estimate and map soil moisture content.

The field measured soil moisture (MS \%) was considered as dependent variable, and $\sigma_{\mathrm{vV}}^{0}$ and SMI were chosen as independent variables. While all test sites were utilized in order to generate model for each taluka separately, while 5 test sites in taluka were used for the accuracy assessment. As a result of multiple regression analysis, mathematical models for soil moisture estimation from $\sigma_{\mathrm{vV}}^{0}$ and SMI were generated for three taluka and these regression equations are as follows:

\section{Godhra Taluka:}

Soil Moisture $\left(\right.$ MS \%) $=0.949 * X_{1}-3.029 * X_{2}+20.065$

$$
\mathrm{R}^{2}=0.788, \text { Adj. } \mathrm{R}^{2}=0.769, \text { Std. Error }=1.376, \mathrm{~N}=25
$$

\section{Goghamba Taluka:}

Soil Moisture $(M S \%)=1.577 * X_{1}-2.514 * X_{2}+24.940$

$$
\mathrm{R}^{2}=0.777, \text { Adj. } \mathrm{R}^{2}=0.755, \text { Std. Error }=1.371, \mathrm{~N}=24
$$

\section{Kalol Taluka:}

Soil Moisture $(M S \%)=1.076 * X_{1}+2.893 * X_{2}+17.909$

$\mathrm{R}^{2}=0.778$, Adj. $\mathrm{R}^{2}=0.754$, Std. Error $=1.090, \mathrm{~N}=21$

Where; $\mathbf{X}_{1}=$ Soil Moisture Index $(\mathrm{SMI})$ and $\mathbf{X}_{\mathbf{2}}=\mathrm{dB}$ $\sigma_{\mathrm{VV}}^{0}$ 
These linear regression equations were used to compute the predicted soil moisture and observed and predicted soil moisture in three talukas are given Figure- 8 .
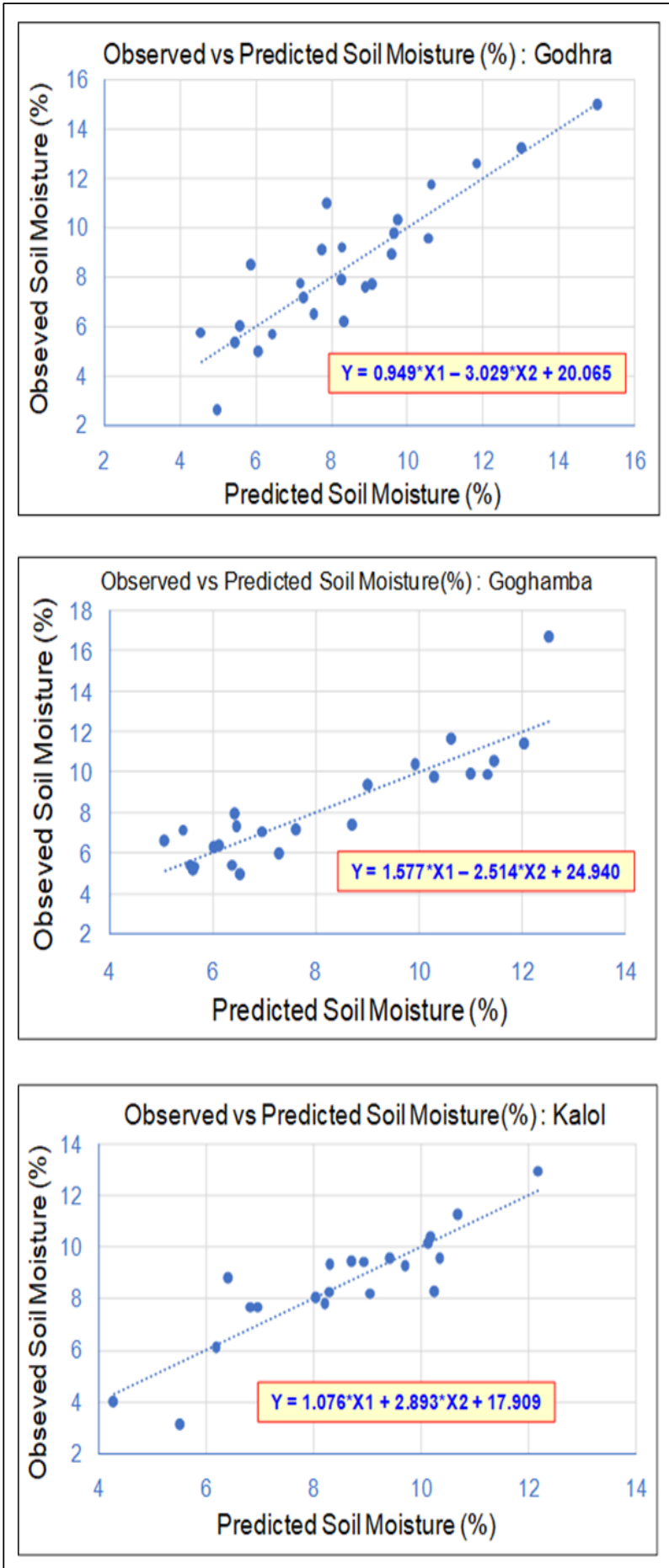

Figure-8: Linear regression analysis between observed and predicted soil moisture in Godhra, Goghamba and Kalol Talukas

\section{Comparison of VV and VH Polarization for Soil Moisture Estimation}

All polarizations of Sentinel-1A data (VV, VH) were analyzed in order to determine which polarization is more sensitive to soil moisture content. The datasets of field measured soil moisture (\%) of sample test sites in each village, $\sigma_{\mathrm{vV}}^{0}(\mathrm{~dB})$, and $\sigma_{\mathrm{VH}}^{0}(\mathrm{~dB})$ were generated and used in regression analysis to estimate soil moisture content. The field measured soil moisture (MS\%) was considered as dependent variable, and $\sigma_{\mathrm{Vv}}^{0}$ and $\sigma_{\mathrm{VH}}^{0}$ (dB) were chosen as independent variables. The results presented in Figure-9 indicated that VV polarization was more sensitive to soil moisture content than the $\mathrm{VH}$ polarization and the coefficient of determination $\left(\mathrm{R}^{2}\right)$ values for $\mathrm{VV}$ and $\mathrm{VH}$ polarizations were determined as 0.72 and 0.276 , respectively in Godhra Taluka.
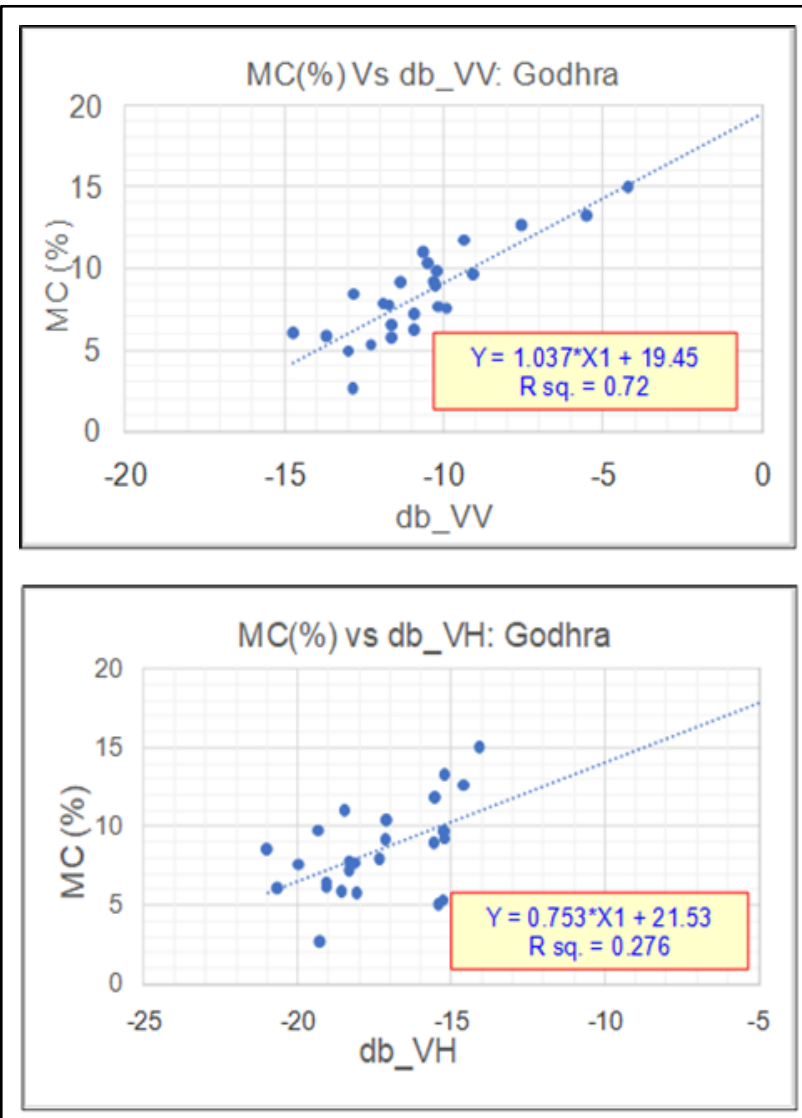

Figure-9: Soil Moisture Estimation Using $\sigma_{\mathrm{VV}}^{0}$ and $\sigma_{\mathrm{VH}}^{0}$ (dB) Polarization in Godhra

\section{Spatial Distribution of Soil Moisture}

In order to map soil moisture distribution, the proposed model was implemented to the images using band math operation in SNAP software developed by ESA. The spatial distribution of soil moisture maps of Godhra and Kalol Talukas are given in Figure-10.

\section{Conclusions}

In this study, Sentinel-1 C-band SAR and Landsat-8 OLI data was analyzed for soil moisture estimation in three talukas of Panchmahal district, Gujarat State. A total number of 70-soil samples were collected near synchronous with respect to the Sentinel-1 acquisition date from the identified sample points in different villages of Godhra, Ghoghamba and Kalol talukas. The in-situ soil moisture content was determined using the gravimetric method. The Sentinel-1 SAR microwave data was analyzed using Open source tools of Sentinel Application Platform (SNAP) software for estimation of backscattering coefficient. The Land Surface Temperature (LST) estimated using Landsat- 8 thermal 
data. The Landsat-8, Thermal infrared sensor Band-10 data and operational land imager Band-4 and Band-5 data were used in estimating LST. The Soil Moisture
Index (SMI) for all field test sites was computed using the LST values.

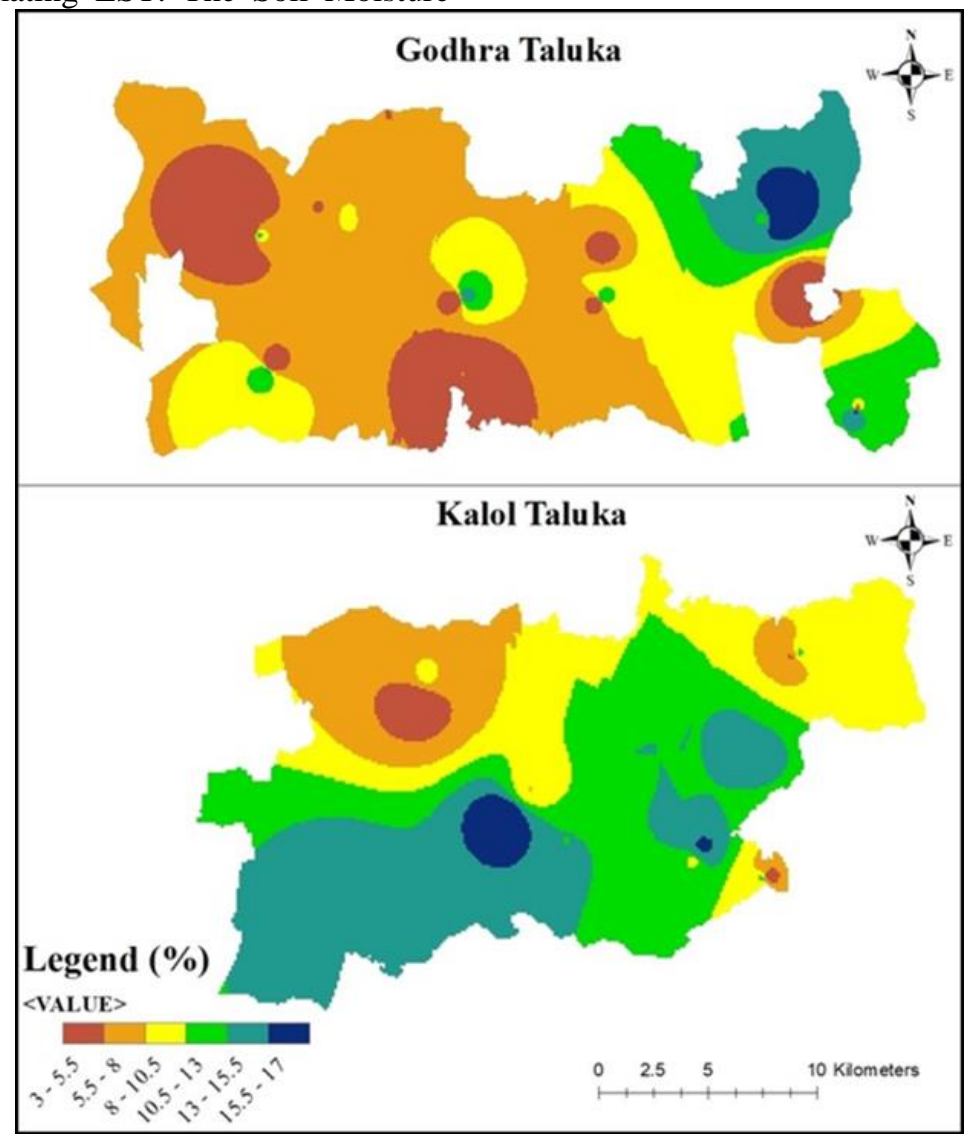

Figure-10: Spatial Distribution of Soil Moisture (\%) Maps of Godhra and Kalol Talukas

The $\sigma_{\mathrm{VV}}^{0}(\mathrm{~dB})$, and $\sigma_{\mathrm{VH}}^{0}(\mathrm{~dB})$ was generated and used in regression analysis to estimate soil moisture content. The field measured soil moisture (MS \%) was considered as dependent variable, and $\sigma_{\mathrm{VV}}^{0}$ and $\sigma_{\mathrm{VH}}^{0}(\mathrm{~dB})$ were chosen as independent variables. The regression analysis using $\sigma_{\mathrm{VV}}^{0}$ and $\sigma_{\mathrm{VH}}^{0}$ polarization with soil moisture indicated that $\sigma_{\mathrm{Vv}}^{0}$ polarization was more sensitive to soil moisture content as compared to $\sigma^{0}{ }_{\mathrm{vH}}$ polarization and the coefficient of determination $\left(\mathrm{R}^{2}\right)$ values for $\sigma_{\mathrm{VV}}^{0}$ and $\sigma_{\mathrm{VH}}^{0}$ polarizations were 0.72 and 0.276 , respectively in Godhra Taluka. The multiple regression analysis using field measured soil moisture (MS \%) as dependent variable, and $\sigma_{\mathrm{vV}}^{0}$ and SMI as independent variables was carried which resulted in the coefficient of determination $\left(\mathrm{R}^{2}\right)$ of $0.788,0.777$ and 0.778 for Godhra, Goghamba and Kalol talukas, respectively. These linear regression equations were used to compute the predicted soil moisture in three talukas. The regression model predicted soil moistures in three talukas were very close to the in-situ measured soil moisture with SEE of 1.376, 1.371 and 1.090 for Godhra, Goghamba and Kalol talukas, respectively. The results of this study indicated that the Sentinel- 1A C-band SAR data is very useful in soil moisture estimation at regional scale.

\section{Acknowledgements}

The authors express their sincere thanks to Director General (DG), Bhaskaracharya Institute for Space Applications and Geo-informatics (BISAG-N), Ministry of Electronics \& Information Technology (MEITY), Government of India, for his keen interest and encouragement to carrying out this study. We are also thankful to Dr. D.K. Vyas, Head of the Department of Renewable Energy Engineering, College of Agricultural Engineering and Technology, Anand Agricultural University, Godhra, Gujarat, India for providing equipment and necessary support to carry out gravimetric soil moisture analysis. The Sentinel-1 data acquired from the European Space Agency (ESA) and Landsat-8 data from United States Geological Survey (USGS) is thankfully acknowledged.

\section{Disclosure statement}

No potential conflict of interest was reported by the authors.

\section{References}

Almaw Ayele Aniley, Naveen Kumar S K, Akshaya Kumar A. (2018). Review Article Soil Moisture Sensors in Agriculture and the possible application of nanomaterials in soil moisture sensors. Ijaert, 6(1), 134-142.

Amato, F., Havel, J., Gad, A., El-Zeiny, A., (2015). Remotely Sensed Soil Data Analysis Using Artificial Neural Networks: A Case Study of El-Fayoum Depression. Egypt. ISPRS International Journal of Geo-Information 4 (2), 677-696. 
Amazirh A., Merlin Olivier, Er-Raki S., Gao Q., Rivalland V., Malbeteau Y., Khabba S., Escorihuela M. J. (2018). Retrieving surface soil moisture at high spatio-temporal resolution from a synergy between Sentinel-1 radar and Landsat thermal data: a study case over bare soil. Remote Sensing of Environment, 211, 321-337.

Ansari, S., Deshmukh, R. R. (2017). Estimation of Soil Moisture Content: A Review. International Journal of Theoretical and Applied Mechanics, 12(3), 571577.

Avdan, U., Jovanovska, G. (2016). Algorithm for Automated Mapping of Land Surface Temperature Using LANDSAT 8 Satellite Data. 2016.

Barrett, B.; Petropoulos, G.P. (2013). Satellite Remote Sensing of Surface Soil Moisture. In Remote Sensing of Energy Fluxes and Soil Moisture Content; CRC Press: Boca Raton, FL, USA, 85-120, ISBN 978-14665-0578-0.

Bezerra, B.G.; Santos, C.A.C.; Silva, B.B.; Perez-Marin, A.M.; Bezerra, M.V.C.; Berzerra, J.R.C.; Rao, T.V.R. (2013). Estimation of soil moisture in the root-zone from remote sensing data. Rev. Bras. Cienc. Solo 2013, 37, 596-603.

Bittelli, M. (2011). Measuring Soil Water Content: A Review. 3861(June), 293-300.

Brdjanovic, D., Meijer, S. C., Lopez-Vazquez, C. M., Hooijmans, C. M., van Loosdrecht, M. C. (Eds.). (2015). Applications of activated sludge models. Iwa Publishing.

Celik, B., Kaya, Ş., Alganci, U., Seker, DZ. (2019). Assessment of the relationship between land use/cover changes and land surface temperatures: a case study of thermal remote sensing, FEB Fresenius Environ. Bull.,3, 541

Chandrasekar, K. Geo-spatial Meteorological Products for Agricultural Drought Assessment, NRSC User Interaction Meet- PPT. 2016. Available online:

Chauhan, S.; Srivastava, H.S. (2016). Comparative evaluation of the sensitivity of multi-polarized SAR nd optical data for various land cover classed. Int. J. Remote Sens. 4, 01-14.

Department of the Interior U.S. Geological Survey. (2016). Landsat 8 Data Users Handbook. Nasa, 8(June), 97.

Drusch, M., Del Bello, U., Carlier, S., Colin, O., Fernandez, V., Gascon, F., Bargellini, P. (2012). Sentinel-2: ESA's Optical High-Resolution Mission for GMES Operational Services. In Remote Sensing of Environment (Vol.120).

Esetlili, M. T., Kurucu, Y. (2016). Determination of Main Soil Properties Using Synthetic Aperture Radar. Fresenius Environmental Bulletin, 25(1), 2336.

Esetlili, M., Bektas Balcik, F., Balik Sanli, F., Kalkan, K., Ustuner, M., Goksel, Ç., Gazioğlu, C., Kurucu, Y. (2018). Comparison of Object and Pixel-Based Classifications for Mapping Crops Using Rapideye Imagery: A Case Study of Menemen Plain, Turkey. International Journal of Environment and Geoinformatics, $5(2), \quad 231-243 . \quad$ DOI: 10.30897/ijegeo.442002.
Filipponi, F. (2019). Sentinel-1 GRD Preprocessing Workflow. Proceedings, 18(1), 11.

Gao, Q.; Zribi, M.; Escorihuela, M.J.; Baghdadi, N. Synergetic use of sentinel-1 and sentinel-2 data for soil moisture mapping at $100 \mathrm{~m}$ resolution. Sensors, 2017.

İncekara, A., Seker, D. Z., Tezcan, C. S., Bozkutoglu, E., Gazioglu, C. (2017). Interpreting temperaturebased discontinuity and roughness of rock surfaces by using photogrammetric technique. International Journal of Environment and Geoinformatics (IJEGEO) ,4(3), 206-213. DOI: 10.30897/ijegeo.348806.

Karjalainen, M.; Kaartinen, H.; Hyyppä, J.; Laurila, H.; Kuittinen, R. (2004). The Use of ENVISAT Alternating Ploarization SAR Images in Agricultureal Monitoring in Compatison with RADARSAT-1 SAR Images. In Proceedings of the ISPRS Congress, Istanbul, Turkey, 12-23 July 2004.

Küçük Matçı, D., Avdan, U. (2019). Optimization of Remote Sensing Image Attributes to Improve Classification Accuracy, International Journal of Environment and Geoinformatics (IJEGEO), 6(1): 50-56. DOI: 10.30897/ijegeo.466985.

Mirsoleimani, H. R., Sahebi, M. R., Baghdadi, N., El Hajj, M. (2019). Bare soil surface moisture retrieval from sentinel-1 SAR data based on the calibrated IEM and dubois models using neural networks. Sensors (Switzerland), 19(14), 1-12.

Moawad, B.M. (2012). Geoscience general tool package. Max-Planck Institute fürChemie, Mainz, Germany.

Mohamed, E.S., Ali, Abdelraouf, El-Shirbeny, Mohammed, Abutaleba, Khaled and Shaddad, Sameh M. (2019). Mapping soil moisture and their correlation with crop pattern using remotely sensed data in arid region. The Egyptian Journal of Remote Sensing and Space Sciences Xxx (xxxx) xxx (Article in Press).

Myhre, B. E., Shih, S. F. (1990). Using Infrared Thermometry to Estimate Soil Water Content for a Sandy Soil. 33 (October), 1479-1486.

Paloscia, S., Pettinato, S., Santi, E., Notarnicola, C., Pasolli, L., Reppucci, A. (2013). Remote Sensing of Environment Soil moisture mapping using Sentinel-1 images: Algorithm and preliminary validation. Remote Sensing of Environment, 134, 234-248.

Petropoulos, G., Carlson, T.N., Wooster, M.J., Islam, S. (2009). A review of T-s/VI remote sensing-based methods for the retrieval of land surface energy fluxes and soil surface moisture Prog. Phys. Geography, 33, 224-250.

Prakash Mohan, M, Rajitha, K. Varma, Murari R (2019). Integration of soil moisture as an auxiliary parameter for the anchor pixel selection process in SEBAL using Landsat 8 and Sentinel - 1A images, International Journal of Remote Sensing, 41:3, 1214123.

Prakash, R.; Singh, D.; Pathak, N.P. A (2012). Fusion approach to retrieve soil moisture with SAR and optical data. IEEE J. Sel. Top. Appl. Earth Obs. Remote Sens. 5, 196-206.

Rahimzadeh-Bajgiran, P., Berg, A.A., Champagne, C., Omasa, K. (2013). Estimation of soil moisture using optical/thermal infrared remote sensing in the 
Canadian Prairies. ISPRS J. Photogrammetry Remote Sens, 83, 94-103.

Rawat, Kishan Singh, Singh, Sudhir Kumar, Ray, Ram Lakhan (2019). An integrated approach to estimate surface soil moisture in agricultural lands, Geocarto International.

Reza Attarzadeh, Jalal Amini, Claudia Notarnicola and Felix Greifeneder (2018). Synergetic Use of Sentinel1 and Sentinel-2 Data for Soil Moisture Mapping at Plot Scale. Remote Sensing, 10, 2 -18.

Sahebi, M.R.; Angles, J.; Bonn, F. (2002). A comparison of multi-polarization and multi angular approaches for estimating bare soil surface roughness from space-borne radar data. Can. J. Remote Sens, 2002, 28, 641-652.

Sekertekin, A., Kutoglu, S.H.; Kaya, Ş. (2016). Evaluation of spatio-temporal variability in land surface temperature: A case study of Zonguldak, Turkey. Environ. Monit. Assess, 188, 30.

Sekertekin, A.; Bonafoni, S. (2020). Land Surface Temperature Retrieval from Landsat 5, 7, and 8 over Rural Areas: Assessment of Different Retrieval Algorithms and Emissivity Models and Toolbox Implementation. Remote Sens. 12, 294.

Sekertekin, Aliihsan, Marangoz, Aycan Murat, and Abdikan, Saygin, (2016). Soil Moisture Mapping Using Sentinel-1A Synthetic Aperture Radar Data. International Journal of Environment and Geoinformatics 5(2): 178- 188 (2016).

Traore, M , Çan, T , Tekin, S . (2020). Discrimination of Iron Deposits Using Feature Oriented Principal Component Selection and Band Ratio Methods: Eastern Taurus /Turkey, International Journal of Environment and Geoinformatics, 7(2), 147-156. doi: 10.30897/ijegeo.673143,

Ulaby, F. T., Moore, R. K., Fung, A. K. (1986). Microwave remote sensing: Active and passive; from theory to applications (Vol. Volume III, 1065-2162).

Wagner, W., Lemoine, G., Borgeaud, M., Rott, H. (1999a). A study of vegetation cover effects on ERS scatterometer data. IEEE Transactions on Geoscience and Remote Sensing, 37(2), 938-948.

Wagner, W., Lemoine, G., Rott, H. (1999b). A method for estimating soil moisture from ERS scatterometer and soil data. Remote Sensing of Environment, 70, 191-207.

Wang, J.R. (1980). The dielectric properties of soilwater mixtures at microwave frequencies. Radio Sci, 1980, 15, 977-985.

Weng, Qihao, Lu, Dengsheng, Schubring, Jacquelyn (2004). Estimation of land surface temperaturevegetation abundance relationship for urban heat island studies. Remote Sensing of Environment 89(4):467-483, February 2004.

Yadav, Vijay Pratap, Rajendra Prasad, Bala, Ruchi, Vishwakarma, Ajeet kumar, (2019). Estimation of soil moisture through water cloud model using sentinel -1A SAR data. Proceeding URSI AP-RASC 2019, New Delhi, India, 09 - 15 March 2019.
Zeng, Y., Feng, Z., Xiang, N. (2004). Assessment of soil moisture using Landsat ETM+ Temperature/vegetation index in semiarid environment. IEEE, 4306-4309.

Zhuo, L.; Han, D. (2016). The relevance of soil moisture by remote sensing and hydrological modelling. Procedia Eng. 154, 1368-1375.

Zribi, M., Baghdadi, N., Holah, N., and Fafin, O. (2005). New methodology for soil surface moisture estimation and its application to ENVISAT-ASAR multi-incidence data inversion. Remote Sensing of Environment, 96(3-4), 485-496. 